\title{
Motivation Factors of the Rowing \& Canoeing Sports Athletes in Thailand
}

\author{
Dr. Chinnaso Visitnitikitja, and Bussarin Sukkeaw \\ Post graduate school of business administration \\ Kasembundit University, Bangkok
}

\begin{abstract}
The primary purpose of this study is to determine motivation factors of the rowing \& canoeing sports athletes in Thailand. Samples were 150 rowing \& canoeing sports athletes in Thailand by using a check list and rating scale questionnaire. The statistics used for data analysis were percentage, mean, standard deviation, T-test, One-way ANOVA, and regression analysis.

On the basis of the results of this study, it can be concluded that most of respondents were males, age between 20-25 years old, bachelor degree graduated, and twelve men boat type. The average picture of opinions in motivation factors of the rowing \& canoeing sports athletes were in the high level, such as reputation, healthy, strong physical, loving, and chances of future flourish. The hypothesis testing revealed that factors of personal different, such as gender, education, type of interesting boat had no effect on motivation factors of the rowing \& canoeing sports athletes in Thailand. In dissimilarity, factor of personal different as age had the effect on motivation factors of the rowing \& canoeing sports athletes in Thailand with statistical significant at 0.05 level.

Recommendations from this study were administrative officers of Rowing \& Canoeing Association of Thailand should consider reasonable benefit and support competition routine match events at all times in order to achieve an excellent games of this sports.
\end{abstract}

Keywords: Motivation Factors

\section{Introduction}

Motivation is very important because it represents the relationship and satisfaction in each aspect, such as love, awareness, health, physical strength, person involved, honor and reputation, career advancement opportunity, therefore the motivation contribute to athletes succeed. Motivations may occur from the trainers or athletes themselves and must find various methods to use as a guideline to motivate the athletes.

The rowing \& canoeing sports have long been in Thailand, there are many rivers in Thailand and boats have been used for festival and ceremonies including National games competition in which regarded as Thai culture that need to be well-preserved.

Long boatamateur association established in 2531, the first associate president wasAdmiral Bundit Choonhawan. In year 2539, Long boat amateur association was approved from the requested and changed the name to Rowing \& Canoeing Association of Thailand to be a legal association. Admiral Thamrong Vibulsatien was a fourth associate president who gives full supports to association and sent rowing seven canoeing sports athletes to complete in $19^{\text {th }}$ SEA Games in 2540 whichwas held in Indonesia with seven countries participating. Rowing \& Canoeing Association of Thailand conquest and received 1 gold, 4 silvers, and 8 bronzesmedals awards. Thedevelopment of rowing\& canoeing sports continuously and be 
able to send athletes to compete in Championship games in Asian, World Championships, and Olympic Games until now.

Physical exercise is good for mind, body and spirit. Furthermore, team sports are good for learning accountability, dedication, and leadership, among many other traits. Putting it all together by playing a sport is a winning combination.

Playing a sport requires a lot of time and energy. Some may think this would distract student-athletes from schoolwork. However, the opposite is true. Sports require memorization, repetition and learning skillsets that are directly relevant to classwork. Also, the determination and goal-setting skills sports require can be transferred to the classroom.

Fighting for a common goal with a host of other players, coaches, managers and community members teaches you how to build a collective team synergy and effectively communicate the best way to solve problems en route to a victory. This will be very helpful in life when encountering problems at work, at home, or in any arena.

Clearly, sports will improve your fitness and weight goals. However, they also encourage healthy decisions such as not smoking or drinking and offer hidden health benefits such as a lower chance of getting osteoporosis or breast cancer later in life. Also, a team counting on you to show up and work hard is plenty of motivation for you to get to the gym day in and day out.

Watching your hard work pay off and achieving your dreams brings about tons of self-confidence. If you can achieve something in a sport or with a fitness goal, then you know you can achieve any other goal you set. This is a very rewarding and exciting process.

Exercising is a natural way to loosen up and let go of stress. Also, you will most likely make many new friends on the team who can be there for you as a support system. When you find you are having a lot of stress, you can call up teammates and head to the gym to talk it out and play it out.For all of these reasons, it is always a great decision to get involved in the sports arena.

From introduction above, researcher are interested in determining of motivation factors of the rowing \& canoeing sports athletes in Thailand and results will be used to set a guideline for the associate to improve athletes' motivation in order to get benefit to rowing \& canoeing Association of Thailand and all athletes.

\section{Purpose of the Study}

The primary purpose of this study is to determine motivation factors of the rowing \& canoeing sports athletes in Thailand.

\section{Research Methodology}

The purpose of this study is to determine motivation factors of the rowing \& canoeing sports athletes in Thailand.To use the data from this study as a guideline in creating motivation forrowing \& canoeing sports athletes in Thailand.

Descriptive statistics were used as data analysis which were frequency, percentage, mean, standard deviation, and also inferential statistics were used for hypothesis testing, such as t-test, and One-way Anova.

\section{Results from the Study}

Factors of personal found that there were 150 respondents, most of respondents were males, age between 20-25 years old, bachelor degree graduated, interested in twelve men boat type.

The average picture of the opinions of factors that influencing motivation of the rowing \& canoeing sports athletes in Thailandwere at highest level consisted of love and wistfulness to rowing \& canoeing sports aspect, health and physical fitness, and high level of opinions with following reasons, such as reputation aspect, career advancement opportunity, and relationship with other persons as shown in figure 1. 


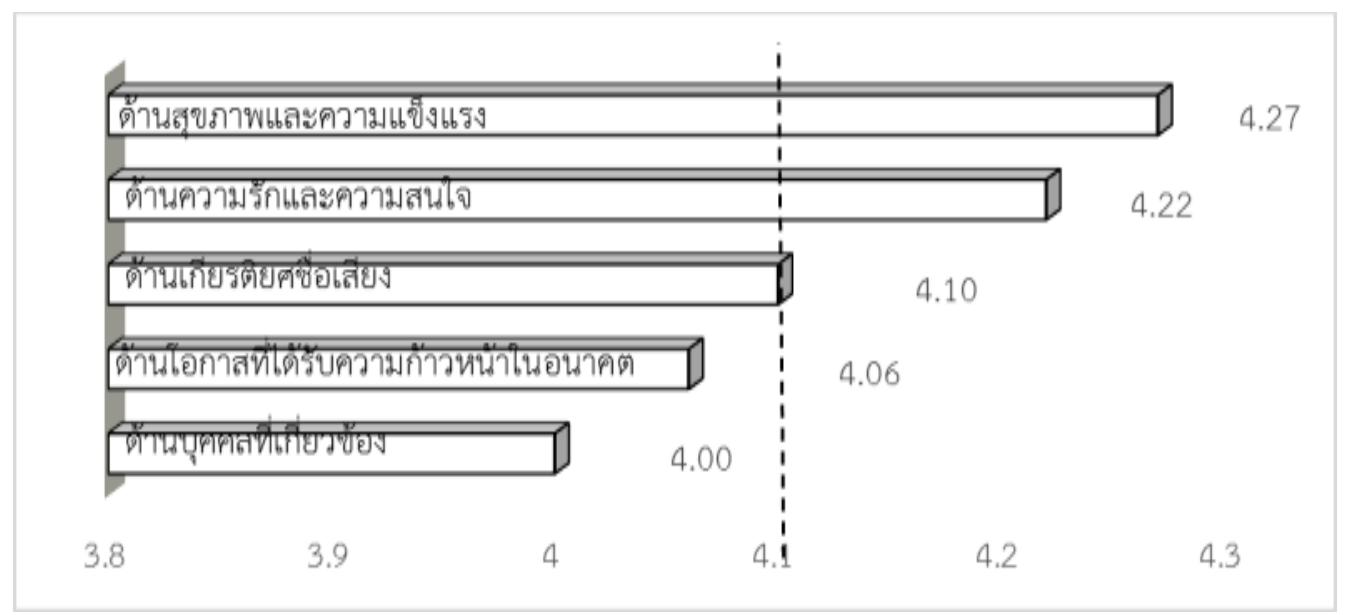

Fig. 1

From figure 2, shows motivation factors of the rowing \& canoeing sports athletes in Thailand.

The average picture of opinionson satisfaction factor of the rowing \& canoeing sports athletes in Thailand were in high level $(\bar{x}=3.95)$

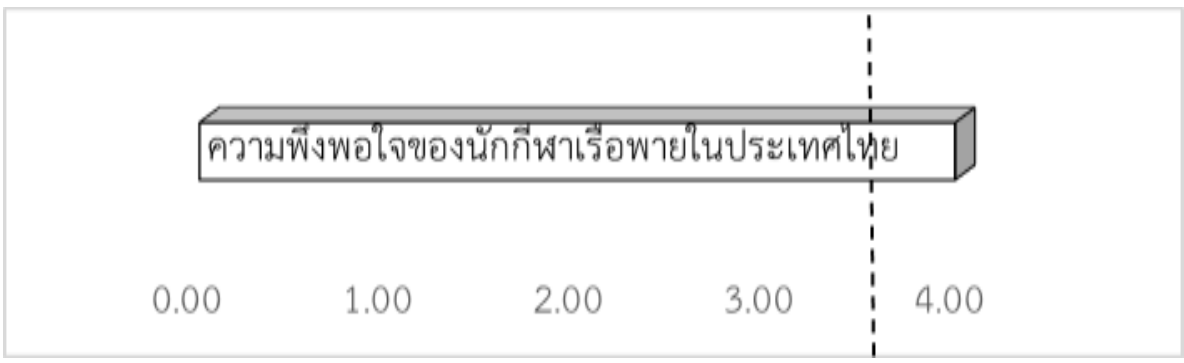

Fig. 2: shows the rowing \& canoeing sports athletes' satisfaction in Thailand.

\section{Test of Hypothesis}

The factors of personal different such as gender, level of education, and type of boat were not affect the rowing \& canoeing sports athletes' satisfaction in Thailand.

The factors of personal different such as age affected the rowing \& canoeing sports athletes' satisfaction in Thailand with statistical significant 0.05 level.

The motivation factors of the rowing \& canoeing sports athletes correlated with job satisfaction of the rowing \& canoeing sports athletes with honor and reputation. In addition, the recognition has been accepted by the others correlated with the rowing \& canoeing sports athletes.

\section{Overview of findings}

From the study of motivation factors of the rowing \& canoeing sports athletes in Thailand consisted of love and wistfulness, health and physical fitness, relationship with others, honor and reputation, career advancement opportunity with the average picture of opinions were at high level which are congruent with Surasak Singsa. (2552).

The motivation of rowing \& canoeing sports athletes in $37^{\text {th }}$ of National games competition with overall pictures of 5 aspects were in high level with the following details: 
Love and attentiveness aspect revealed that the picture of opinions were in medium level are congruent with the research on motivation factors on choosing wrestling sport in Thailand. (Jitratda Rattanatevath, 2550).

Health and physical fitness aspect revealed that the picture of opinions were in high level are congruent with the research on motivation factors on choosing Thai boxing of male students in Petchabun education dictrict. (Somnuek Bunnag, 2548).

People involved in choosing the rowing \& canoeing sport aspect revealed that the picture of opinions were in high level are congruent with the research on the motivation of rowing \& canoeing sports athletes in 37th of National games competition. (Surasak Singsa, 2552).

Honor and reputation aspect revealed that the picture of opinions were in high level are congruent with the research on the motivation of rowing \& canoeing sports athletes in 37th of National games competition. (Surasak Singsa, 2552).

Career advancement opportunity aspect revealed that the picture of opinions were in high level are congruent with the research on motivation of rowing \& canoeing sports athletes in 37th of National games competition. (Surasak Singsa, 2552).

\section{Recommendation from the Study}

Recommendations from this study were that administrative officers of Rowing \& Canoeing Association of Thailand should consider recruiting athletes who are interest in sport and develop their skills to full capacity, develop health and physical fitness to be prepared for the next games, involve with their families to get support from them, routine training, career advancement opportunity planning to become professional athlete, reasonable benefit, and support competition routine match events at all times in order to achieve an excellent Games of this sports.

\section{References}

[1] Sports Authority of Thailand. (2542). Exercises for health. Seven printing group co., Ltd., Bangkok.

[2] Kamolrat Lahsuwong. (2530). Psychology of Education, revised edition. $2^{\text {nd }}$ ed. Odian Store, Bangkok.

[3] Kitti Tayakcanont. (2533). Modern Management. $2^{\text {nd }}$ edition, Butterfly printing, Bangkok.

[4] Jitradda Rattanatevath. (2550). Motivation factors of wrestling sport selection of athletes In Thailand. Thesis, Graduate School, Srinakarintaraviroj University.

[5] Termsak Catavanich. (2546). General Psychology. $2^{\text {nd }}$ edition, Butterfly printing, Bangkok.

[6] Tavil Guergulvong. (2528). Work performance motivator. Silapakorn University Printing, Nakorn Prathom Province.

[7] Taves Piriyapruen. (2545). Research in physical education. Srinakarintaraviroj University.

[8] Pichit Muangnapoh. (2534). Teaching Manuel. Sport Psychology, Physical education department Srinakarintaraviroj University.

[9] Lakkana Srivath. (2530). Principle of Psychology, Odian Store, Bangkok.

[10] Siriwan Saerirat. (2541). Personnel performance satisfaction. Thai Wattana Panich, Bangkok.

[11] Rowing \& canoeing sports Association. (2558). Long-boat traditional History. http://www.rcat.or.th

[12] Somnuek Bunnag, (2548). Motivation factors on choosing Thai boxing of male students in Petchabun education dictrict. Graduate school, Srinakarintaraviroj University.

[13] Surasak Singsa, (2552). Motivation of rowing \& canoeing sports athletes in 37th of National games competition. Physical Education Department, Srinakarintaraviroj University.

[14] Supranee Khanboonchan. (2541). Sport Psychology. Thai Wattana Panich pulisher, Bangkok.

[15] Somyos Naveegarn. (2533). Work performance satisfaction. Thai Wattana Panich pulisher, Bangkok. 